\title{
Inhibition of Metal Hydrogenation Catalysts by Biogenic Impurities
}

\author{
Thomas J. Schwartz • Zachary J. Brentzel • \\ James A. Dumesic
}

Received: 30 September 2014/ Accepted: 14 November 2014/Published online: 22 November 2014

(C) Springer Science+Business Media New York 2014

\begin{abstract}
We show that supported Ni, Pt, and Pd catalysts used for liquid phase hydrogenation are inhibited by the biogenic impurities present in biologically-derived feedstocks used to produce high-value chemicals. The effects of thiamine $\mathrm{HCl}$, cysteine, methionine, biotin, tryptophan, niacin, threonine, and $p$-aminobenzoic acid were elucidated by collecting adsorption isotherms of these species and by quantifying their influence on the rate of cyclohexene hydrogenation at $323 \mathrm{~K}$. Inhibition increases in the order of $\mathrm{Pd}<\mathrm{Pt}<\mathrm{Ni}$ and generally correlates with the binding energies of sulfur and nitrogen. The equilibrium constants reported here for adsorption of these species on $\mathrm{Ni}, \mathrm{Pt}$, and $\mathrm{Pd}$ can facilitate the design of separation systems and new catalysts used for upgrading biologically-produced platform molecules.
\end{abstract}

Keywords Heterogeneous catalysis - Hydrogenation · Biogenic impurities - Catalyst stability · Biorenewable chemicals

\section{Introduction}

Various strategies have been described for the upgrading of renewable biomass resources for the sustainable production of fuels and chemicals [1-4]. One such strategy leverages the high efficiency of heterogeneous chemical catalysis to upgrade platform intermediates that are produced using biocatalysis [5-8]. These platform intermediates often contain unsaturated carbon-carbon or carbon-oxygen

T. J. Schwartz · Z. J. Brentzel · J. A. Dumesic $(\varangle)$ Department of Chemical and Biological Engineering, University of Wisconsin-Madison, 1415 Engineering Drive, Madison, WI, USA

e-mail: dumesic@engr.wisc.edu bonds that must be reduced using metal catalysts, for example in the conversion of lactic acid to propylene glycol [9, 10], hydrogenation of succinic acid [11, 12], and the conversion of triacetic acid lactone to sorbic acid, lactones, and bifunctional ketones [13].

Inhibition of reduced metal catalysts by biogenic impurities is an important challenge for the catalytic upgrading of biologically-derived species. Indeed, when real fermentation products are used as feedstocks, it is often observed that reduced metal catalysts operate at low activity [14, 15], attributed to the presence of residual impurities from the fermentation. Glutathione, for example, contains a thiol group and is inhibitory towards homogeneous Ir catalysts. However, some catalytic activity can be recovered by oxidizing the thiol using diamine [16]. Hollmann and coworkers have also shown that proteins and amino acids bind strongly to homogeneous Rh complexes, leading to decreased activity [17]. Miller and coworkers [18] studied the influence of several representative impurities on lactic acid hydrogenation, and they observed that salts, organic acids, extraction solvents, and carbohydrates have a minimal effect on $\mathrm{Ru}$ catalysts. In contrast, the addition of bovine albumin as a model protein resulted in catalyst deactivation due to pore plugging, and $100 \mathrm{ppm}$ of the sulfur-containing amino acids cysteine and methionine caused irreversible catalyst deactivation. The effect of cysteine and methionine was attributed to the presence of sulfur groups, because a sulfur-free amino acid (alanine) caused only moderate, reversible catalyst inhibition. We have recently observed a similar phenomenon during the hydrogenation of triacetic acid lactone [19], noting that methionine has a strong inhibitory effect on $\mathrm{Pd}$ and $\mathrm{PdAu}$ catalysts, while alanine and tryptophan have a more moderate influence.

In the present work, we use the liquid-phase hydrogenation of cyclohexene as a probe reaction to elucidate the 
inhibitory effects of functional groups that are common to a set of representative biogenic impurities. Benefiting from the well-documented kinetics of cyclohexene hydrogenation using Pt [20], Pd [21], and Ni [22], we have measured the hydrogenation rate in the presence of four representative amino acids and four representative vitamins. These data were then used to quantify the effects of the impurities on $\mathrm{Pt}, \mathrm{Pd}$, and $\mathrm{Ni}$, and we elucidate the inhibitory effects of the various functionalities present in these biogenic impurities. Knowledge of such inhibitory effects is crucial for the rational design of processes that combine chemical and biological catalysis.

\section{Experimental}

\subsection{Catalyst Synthesis and Characterization}

Catalysts were prepared by incipient wetness impregnation of either $\gamma-\mathrm{Al}_{2} \mathrm{O}_{3}$ (Strem, low-soda) or $\mathrm{SiO}_{2}$ (Davisil Grade 646, crushed and sieved between 50 and 100 mesh) with aqueous solutions of $\mathrm{Pd}\left(\mathrm{NO}_{3}\right)_{2}$ (prepared from Aldrich $10 \% \mathrm{Pd}\left(\mathrm{NO}_{3}\right)_{2}$ solution in $\left.10 \% \mathrm{HNO}_{3}, 99.999 \%\right)$, $\mathrm{H}_{2} \mathrm{PtCl}_{6}$ (Aldrich, $>99.9 \%$ ), or $\mathrm{Ni}\left(\mathrm{NO}_{3}\right)_{2}$ (Acros Organics, $99.99 \%)$. The catalysts were subsequently dried in air at $383 \mathrm{~K}$ for $2 \mathrm{~h}$, calcined in flowing air at $673 \mathrm{~K}$, reduced in flowing hydrogen (533 K for Pd, $673 \mathrm{~K}$ for Pt and Ni), and passivated with $1 \% \mathrm{O}_{2}$ in Ar. Pd catalysts supported on $\mathrm{SiO}_{2}$ were prepared by ion exchange of $\mathrm{Pd}\left(\mathrm{NO}_{3}\right)_{2} \cdot 4 \mathrm{NH}_{3}$ (Aldrich $10 \% \mathrm{Pd}\left(\mathrm{NO}_{3}\right)_{2} \cdot 4 \mathrm{NH}_{3}$ solution in water). In this method, $5 \mathrm{~g}$ of $\mathrm{SiO}_{2}$ were first suspended in $125 \mathrm{~mL}$ of Milli-Q grade water. The $\mathrm{pH}$ of the suspension was raised to 11 using concentrated $\mathrm{NH}_{4} \mathrm{OH}$ (Sigma-Aldrich, ACS Reagent 28-30\% $\mathrm{NH}_{3}$ basis), following which the appropriate amount of $\mathrm{Pd}\left(\mathrm{NO}_{3}\right)_{2} \cdot 4 \mathrm{NH}_{3}$ solution was added dropwise. The mixture was filtered and washed with Milli$\mathrm{Q}$ grade water until the filtrate was neutral. The catalyst was then dried in air at $383 \mathrm{~K}$ for $2 \mathrm{~h}$, calcined in flowing air at $573 \mathrm{~K}$, reduced in flowing hydrogen at $533 \mathrm{~K}$, and passivated with $1 \% \mathrm{O}_{2}$ in $\mathrm{Ar}$.

The CO uptake (99.99\%) for each catalyst was measured using an apparatus and procedure described previously [23]. Pt dispersion was determined using a stoichiometry of $1 \mathrm{CO}$ per surface metal atom. Pd [24] and $\mathrm{Ni}$ [25] dispersions were determined using a stoichiometry of $0.5 \mathrm{CO}$ per surface metal atom.

\subsection{Reaction Kinetics Measurements}

Cyclohexene hydrogenation was carried out in Hastelloy pressure vessels (Parr Instrument, Multireactor System MRS 5000). The catalyst and magnetic stir bar were loaded into the reactor with methanol. The vessel was then sealed, purged with $\mathrm{He}$, pressurized with 30 bar of $\mathrm{H}_{2}$, and stirred at $550 \mathrm{rpm}$. The Ni catalyst was reduced at $388 \mathrm{~K}$ for $1 \mathrm{~h}$, and the Pt and $\mathrm{Pd}$ catalysts were reduced at $323 \mathrm{~K}$ for $1 \mathrm{~h}$. After reduction, methanol solutions of the impurity under study were pumped into the reactor using an HPLC pump. The catalyst was equilibrated for $45 \mathrm{~min}$ at $323 \mathrm{~K}$, following which cyclohexene was pumped into the reactor using a syringe pump (defined as $\mathrm{t}=0$ ). Hydrogen consumption during the reaction at $323 \mathrm{~K}$ was monitored by recording the reactor headspace pressure using an electronic pressure transducer (Ashcroft, model G6). The hydrogen consumption rate was determined by evaluating the rate constant using published rate expressions for cyclohexene hydrogenation. The reactions are known to be zero-order with respect to cyclohexene on all three metals, half-order with respect to hydrogen on $\mathrm{Ni}$ and $\mathrm{Pd}$, and first-order with respect to hydrogen on $\mathrm{Pt}$ [20-22]. Cyclohexene consumption and cyclohexane production were verified for selected reactions by gas chromatography (Shimadzu GC2010 equipped with an FID and a DB-5MS capillary column). Methanol (Sigma-Aldrich, Chromasolv Plus), methionine (Sigma-Aldrich, $\geq 98 \%$ ), cysteine (SigmaAldrich, $\geq 98 \%$ ), tryptophan (Sigma-Aldrich, $\geq 98 \%$ ), threonine (Sigma-Aldrich, $\geq 98 \%$ ), thiamine $\mathrm{HCl}$ (SigmaAldrich, $\geq 98 \%$ ), biotin (Sigma-Aldrich, $\geq 98 \%$ ), niacin (Sigma-Aldrich, $\geq 98 \%$ ), and $p$-aminobenzoic acid (SigmaAldrich, $\geq 98 \%$ ) were used as purchased. Cyclohexene is known to undergo auto-oxidation in air [26, 27], and these oxidation products have a detrimental effect on catalyst stability. Thus, the reactions performed here used cyclohexene containing butylated hydroxytoluene as an oxidation inhibitor (Sigma-Aldrich, $\geq 99 \%$ ).

\subsection{Adsorption of Biogenic Impurities on Metal Catalysts}

Adsorption of biogenic impurities on the Pt and Pd catalysts was carried out in thick-walled glass batch reactors (Alltech, $10 \mathrm{~mL}$ ) sealed with Teflon septa inserted into plastic caps. The magnetic stir bar, catalyst (approximately $20 \mathrm{mg}$ ), and methanol were loaded into the reactor, which was then sealed, purged with $\mathrm{He}$, and purged with $\mathrm{H}_{2}$. The reactors were placed in an oil bath that was maintained at $323 \mathrm{~K}$, and the catalysts were reduced for $1 \mathrm{~h}$ with 1 bar of hydrogen. After reduction, methanol solutions of the inhibitor were injected into the reactor using a syringe. The reactors were equilibrated for $1 \mathrm{~h}$, following which they were sampled at $323 \mathrm{~K}$. A similar procedure was used for $\mathrm{Ni}$ (approximately $50 \mathrm{mg}$ ), which was pre-reduced both with and without methanol for $1 \mathrm{~h}$ at $388 \mathrm{~K}$ in Hastelloy autoclaves (the presence of methanol was not observed to influence the reduction of the $\mathrm{Ni}$ catalyst). After reduction, methanol solutions of the inhibitor were added to the vessels using an HPLC pump. The apparent uptake was 
determined by measuring the difference in inhibitor concentration before and after equilibration with the catalyst.

Concentrations of thiamine, biotin, niacin, and $p$-aminobenzoic acid were measured using a high performance liquid chromatograph (Waters Alliance 2695) equipped with a photodiode array detector (Waters 996). Separation was achieved with a reversed-phase Zorbax SB-C18 column (Agilent Technologies) using $5 \mathrm{mM} \mathrm{H}_{2} \mathrm{SO}_{4}$ as the aqueous phase, with acetonitrile as the organic modifier. Concentrations of the amino acids were measured by HPLC using a precolumn derivatization procedure based on that of Kinoshita and coworkers [28]. Solution A consisted of the sample mixed with an equal volume of acetonitrile (Sigma-Aldrich, Chromasolv Gradient Grade) to which triethylamine (SigmaAldrich, $\geq 99 \%$ ) was added to yield a concentration of $0.4 \%$ (w/v). Solution B consisted of $0.2 \% \mathrm{w} / \mathrm{v}$ 2,3,4,6-tetra- $O$ acetyl- $\beta$-D-glucopyranosyl isothiocyanate (GITC) (Sigma, $\geq 98 \%$ ) in acetonitrile. A $50 \mu \mathrm{L}$ aliquot of solution A was mixed with an equal volume of solution $\mathrm{B}$, and the mixture was allowed to stand at room temperature for $1 \mathrm{~h}$. After the mixture was allowed to stand, $10 \mu \mathrm{L}$ of $0.25 \%$ (w/v) monoethanolamine (Sigma-Aldrich, $\geq 98 \%$ ) in acetonitrile was added to remove the GITC peak from the chromatogram when analyzing methionine. The samples were injected on the HPLC described above. While the aqueous phase (solvent A) remained the same, the organic modifier was switched to methanol (solvent B). The gradient was as follows: $40 \% \mathrm{~B}$ (0-5 min); 40-45\% B (5-6 min); $45 \%$ B (6-11 min); $45-50 \%$ B (11-12 min); $50 \%$ B (12-12 min); 50-55 \% B (22-23 min); $55 \%$ B (23-43 min).

\section{Results}

The adsorption stoichiometries of eight representative biogenic impurities were determined for platinum, palladium, and nickel (see Fig. 1; Table 1). Importantly, catalysts supported on $\gamma-\mathrm{Al}_{2} \mathrm{O}_{3}$ showed complete uptake of species containing a carboxylic acid functional group, even when numerous monolayer (ML) equivalents of the impurity were dosed into the reactor (i.e., more micromoles of the impurity than micromoles of surface metal). Such behavior indicates that carboxylic acid groups adsorb on both the metal and the support, consistent with our previous observations [19]. Species containing carboxyl groups did not adsorb on $\mathrm{SiO}_{2}$. Therefore, the stoichiometries were measured using $\mathrm{SiO}_{2}$ supported catalysts. The change of support was not observed to affect the uptake for thiamine, which does not contain a carboxylic acid group, suggesting that metal-support interactions do not play a significant role in the adsorption of biogenic impurities on reduced metals at these conditions.

Figure 1 shows adsorption isotherms for all eight species on $\mathrm{SiO}_{2}$-supported $\mathrm{Pd}, \mathrm{Pt}$, and $\mathrm{Ni}$. The saturation uptake (i.e., $\mu m o l$ uptake of impurity divided by the $\mu \mathrm{mol}$ of surface metal atoms) for each impurity is reported in Table 1. The uptakes of these species are less than unity, with the exception of the uptake for cysteine on all three metals and the uptake of methionine on Pd. Additionally, the uptake of niacin in the presence of $\mathrm{Pt}$ and Pd exceeds what can be accounted for by the total amount of surface metal loaded in the reactor. However, niacin was not observed to bind in large quantities to the $\mathrm{SiO}_{2}$ support. Exposing $\mathrm{Pd}$ to a concentrated niacin solution at the same conditions led to the formation of nipecotic acid, which is the hydrogenated analogue of niacin. This observation is consistent with reports of the hydrogenation of pyridine derivatives at mild conditions [29].

$\mathrm{Pt}, \mathrm{Pd}$, and Ni catalysts were prepared at two different metal loadings to verify the absence of internal mass transport limitations. As shown in Table 2, the TOF was observed to be invariant with changes in the site density for each metal, which indicates the absence of mass transport limitations [30]. The reaction rates were consistent with published rates that were collected at room temperature and scaled to $323 \mathrm{~K}$ [20-22].

Figure 2 shows the reactivity profiles obtained using the eight representative biogenic impurities. It has been shown that the TOF for cyclohexene hydrogenation on sulfurpoisoned Pt remains constant when calculated using the number of vacant (i.e., un-poisoned) sites [31]. Thus the rates measured here should scale with the fraction of available sites and can be used to determine an apparent adsorption equilibrium constant for each impurity. This scaling is described by Eq. 1, where $r$ is the rate measured after exposure to an impurity, $r_{0}$ is the rate in the absence of any impurities, and $\theta *$ is the fraction of available sites. In accordance with the observation that the saturation coverage by most of the impurities was a fraction of the total number of surface sites, it was assumed that one molecule occupies two surface sites. This assumption leads to the equilibrium constant, $K_{\text {ads }}$, defined in Eq. 2, where $C_{\text {inhib }}$ is the equilibrium concentration of the inhibitor. In the cases of methionine adsorption on Pd and cysteine adsorption all three metals, it was assumed that a single molecule adsorbs to a single site, according to Eq. 3. The apparent adsorption equilibrium constant was evaluated using the 'nlinfit' function in MATLAB, and the uncertainties of the fitted parameters were calculated with the 'nlparci' function. Table 3 shows the fitted equilibrium constants and $95 \%$ confidence intervals.

$$
\begin{aligned}
& \frac{r}{r_{0}}=\theta_{*} \\
& K_{\text {ads }}=\frac{1-\theta_{*}}{C_{\text {inhib }} \theta_{*}^{2}}
\end{aligned}
$$


Fig. 1 Adsorption isotherms measured on $\mathrm{Pt} / \mathrm{SiO}_{2}$ (filled square), $\mathrm{Pd} / \mathrm{SiO}_{2}$ (white circle), and $\mathrm{Ni} / \mathrm{SiO}_{2}$ (filled triangle) for a thiamine $\mathrm{HCl}, \mathbf{b}$ cysteine, c methionine, $\mathbf{d}$ biotin, e tryptophan, $\mathbf{f}$ niacin, g threonine, and

$\mathbf{h} p$-aminobenzoic acid
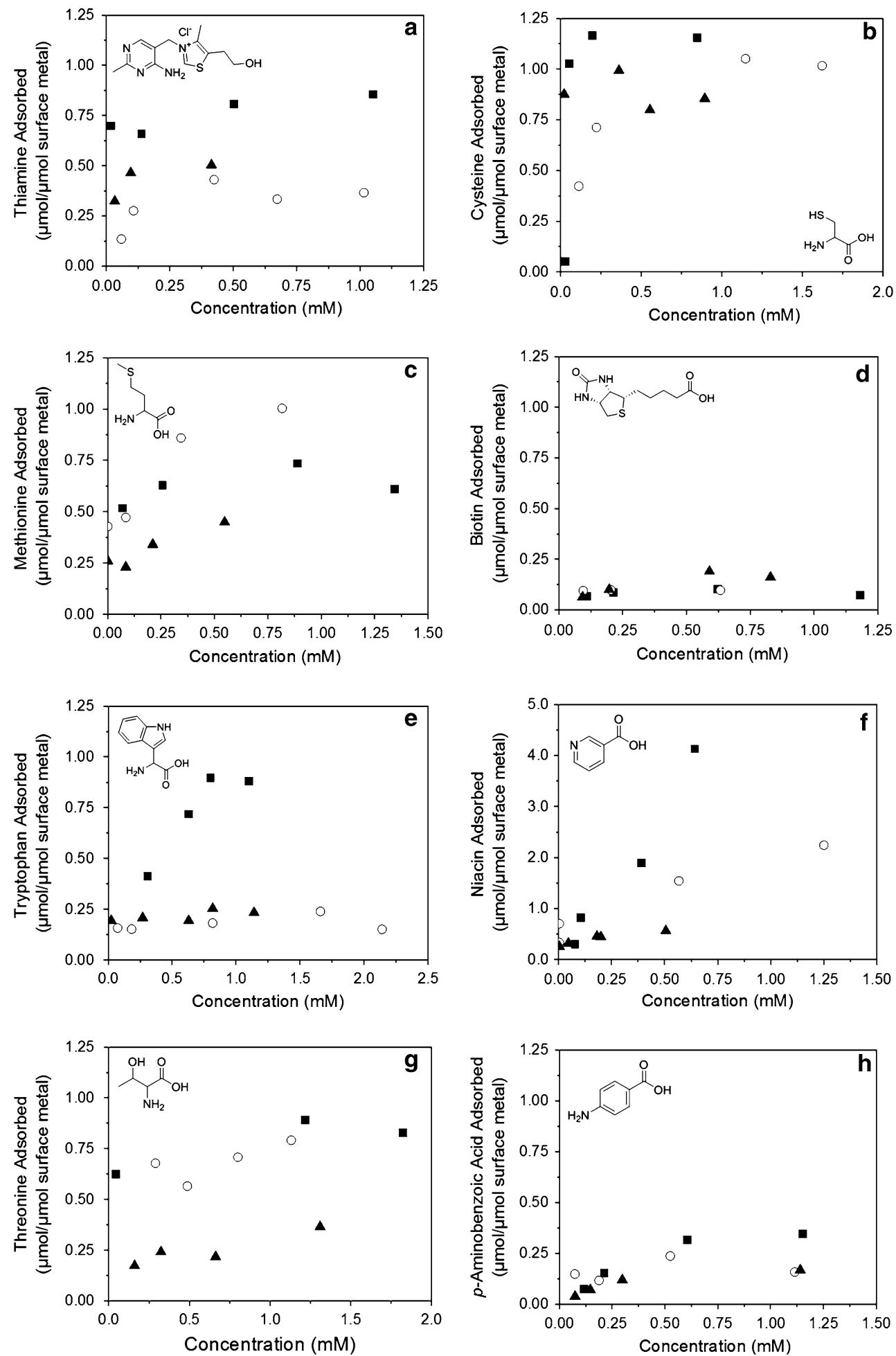

$K_{\mathrm{ads}}=\frac{1-\theta_{*}}{C_{\mathrm{inhib}} \theta_{*}}$

The adsorption of the sulfur-containing compounds (i.e., methionine, cysteine, thiamine, and biotin) is associated with high apparent adsorption equilibrium constants, while the equilibrium constants determined for the remaining compounds are low by comparison. This trend is conserved across all three metals, although each metal varies in its overall resistance to inhibition. Importantly, $\mathrm{Ni}$ is the least tolerant of biogenic impurities, while Pd shows a higher 
tolerance towards the inhibitors. Pt is more tolerant than $\mathrm{Ni}$ but less so than Pd. Thiamine, a sulfur- and chlorine-containing vitamin, and cysteine, a sulfur-containing amino acid, are the most inhibitory compounds. In contrast, $p$-aminobenzoic acid has the least effect on all three metals. Importantly, threonine has a minimal effect on all three metals. Given that threonine possesses only a hydroxyl group attached to an aliphatic side chain, this behavior is an indication that the amino acid functionality is not a strong inhibitor of $\mathrm{Pt}, \mathrm{Pd}$, or $\mathrm{Ni}$. All eight impurities have a stronger effect on $\mathrm{Ni}$ than on the other two metals, suggesting that base metals are more susceptible to deactivation by biogenic impurities than are noble metals.

\section{Discussion}

We have shown that biogenic impurities can have a substantial, detrimental effect on supported metal catalysts. The strongest inhibitors are species that contain sulfur, including the amino acids methionine and cysteine as well as the vitamins biotin and thiamine. Of the metals investigated here, $\mathrm{Pd}$ was the least inhibited by biogenic

Table 1 Saturation uptake of representative biogenic impurities on $\mathrm{Pt}, \mathrm{Pd}$, and $\mathrm{Ni}$ ( $\mu \mathrm{mol}$ impurity $/ \mu \mathrm{mol}$ metal)

\begin{tabular}{lcll}
\hline & Uptake on Pt & Uptake on Pd & Uptake on Ni \\
\hline Thiamine $\mathrm{HCl}$ & 0.7 & 0.3 & 0.5 \\
Cysteine & 1.0 & 1.0 & 0.9 \\
Methionine & 0.6 & 1.0 & 0.4 \\
Biotin & 0.1 & 0.1 & 0.2 \\
Tryptophan & 0.9 & 0.2 & 0.2 \\
Niacin & $-^{\mathrm{a}}$ & $-^{\mathrm{a}}$ & 0.4 \\
Threonine & 0.8 & 0.7 & 0.3 \\
$p$-Aminobenzoic acid & 0.3 & 0.2 & 0.2
\end{tabular}

$\overline{{ }^{a}}$ Multiple monolayer equivalents of niacin were taken up by $\mathrm{Pt}$ and $\mathrm{Pd}$ impurities. In contrast, Ni was inhibited significantly at low loadings of all eight of the impurities. Importantly, our results generally show increasing inhibition in the order $\mathrm{Pd}<\mathrm{Pt}<\mathrm{Ni}$. This order follows the same trend as the adsorption energies of atomic sulfur and atomic nitrogen as calculated by density functional theory for close-packed metal surfaces (i.e., metal-sulfur binding energies of $-4.9 \mathrm{eV}$ for $\mathrm{Ni},-4.7 \mathrm{eV}$ for $\mathrm{Pt}$, and $-4.5 \mathrm{eV}$ for $\mathrm{Pd}$ along with metal-nitrogen binding energies of $-4.6 \mathrm{eV}$ for $\mathrm{Ni}$, $-4.0 \mathrm{eV}$ for $\mathrm{Pt}$, and $-3.7 \mathrm{eV}$ for $\mathrm{Pd}$ ) [33]. This qualitative correlation indicates that the species bind through the sulfur atom when sulfur is present, and binding involves a nitrogen atom in the absence of sulfur.

It is notable that the amount of methionine taken up by $\mathrm{Pt}$ and Ni corresponds to between 0.4 and 0.6 ML equivalents, whereas $\mathrm{Pd}$ takes up approximately one ML equivalent. This disparity suggests that the $\mathrm{S}$ atom in methionine binds to multiple $\mathrm{Pt}$ or $\mathrm{Ni}$ surface atoms. Notably, methionine adsorbs with nearly a 1:1 stoichiometry on $\mathrm{Pd}$, in contrast to the low saturation coverage expected for atomic sulfur on close-packed Pd surfaces [34]. We have previously shown that at these conditions methionine decomposes to $\mathrm{SCH}_{3}$ moieties that bind to the Pd catalyst, but that it does not decompose completely to yield atomic sulfur [19]. In contrast, the fractional uptake observed on $\mathrm{Pt}$ and $\mathrm{Ni}$ is consistent with the saturation coverage by atomic sulfur on the close-packed facets of each metal $[35,36]$. These results, then, are suggestive of the decomposition of methionine to form atomic sulfur on $\mathrm{Pt}$ and $\mathrm{Ni}$.

Cysteine adsorbs with a stoichiometry near 1:1 on all three metals, and its inhibitory effect follows the same general trend as the DFT-calculated metal-sulfur adsorption energies [33]. This trend, combined with the observed adsorption stoichiometry, suggests that cysteine binds directly to the metal surface through its terminal sulfur atom but without decomposition to form atomic sulfur. Thiamine strongly inhibits all three metals and binds to a

Table 2 Catalyst characterization data and base-case reaction rates

\begin{tabular}{|c|c|c|c|c|c|}
\hline Catalyst & Nominal metal loading $\left(\mu \mathrm{mol} \mathrm{g}^{-1}\right)$ & CO uptake $\left(\mu \mathrm{mol} \mathrm{g}{ }^{-1}\right)$ & Dispersion $(\%)^{\mathrm{a}}$ & TOF $\left(\mathrm{s}^{-1}\right)^{\mathrm{a}}$ & Literature TOF $\left(\mathrm{s}^{-1}\right)^{\mathrm{b}}$ \\
\hline $0.1 \% \mathrm{Pt} / \mathrm{Al}_{2} \mathrm{O}_{3}$ & 5.1 & 2.7 & 53 & 10.7 & 13 \\
\hline $0.25 \% \mathrm{Pt} / \mathrm{Al}_{2} \mathrm{O}_{3}$ & 12.8 & 7.3 & 57 & 10.3 & - \\
\hline $0.1 \% \mathrm{Pd} / \mathrm{Al}_{2} \mathrm{O}_{3}$ & 9.4 & 2.3 & 48 & 14.9 & 14 \\
\hline $0.2 \% \mathrm{Pd} / \mathrm{Al}_{2} \mathrm{O}_{3}$ & 18.8 & 3.3 & 35 & 15.2 & - \\
\hline $1.5 \% \mathrm{Ni} / \mathrm{SiO}_{2}$ & 256 & 9.8 & 8 & 0.35 & 0.36 \\
\hline $3.0 \% \mathrm{Ni} / \mathrm{SiO}_{2}$ & 511 & 33.5 & 13 & 0.30 & - \\
\hline
\end{tabular}

Rates determined by integrating the rate law [20-22] over the initial $20 \%$ conversion. Reaction conditions: $323 \mathrm{~K}, 30$ bar $\mathrm{H}_{2}, 15 \%$ cyclohexene in methanol [mol cyclohexene: mol surface metal $=3,700(\mathrm{Ni}), 145,000(\mathrm{Pd}), 120,000(\mathrm{Pt})]$

${ }^{a}$ Dispersion and TOF based on surface metal atoms determined using a stoichiometry of $1 \mathrm{CO} / \mathrm{Pt}, 0.5 \mathrm{CO} / \mathrm{Pd}$ [24], and 0.5 CO/Ni [25].

b TOF scaled to $323 \mathrm{~K}$ from rate data collected at room temperature [20-22] 
Fig. 2 Reactivity profiles showing inhibition of $\mathrm{Pt} / \mathrm{Al}_{2} \mathrm{O}_{3}$ (filled square), $\mathrm{Pd} / \mathrm{Al}_{2} \mathrm{O}_{3}$ (white circle), and $\mathrm{Ni} / \mathrm{SiO}_{2}$ (filled triangle) by a thiamine $\mathrm{HCl}$, b cysteine, c methionine, d biotin, e tryptophan, f niacin, $\mathbf{g}$ threonine, and $\mathbf{h} p$-aminobenzoic acid, with the rates normalized to the rate in the absence of inhibitors
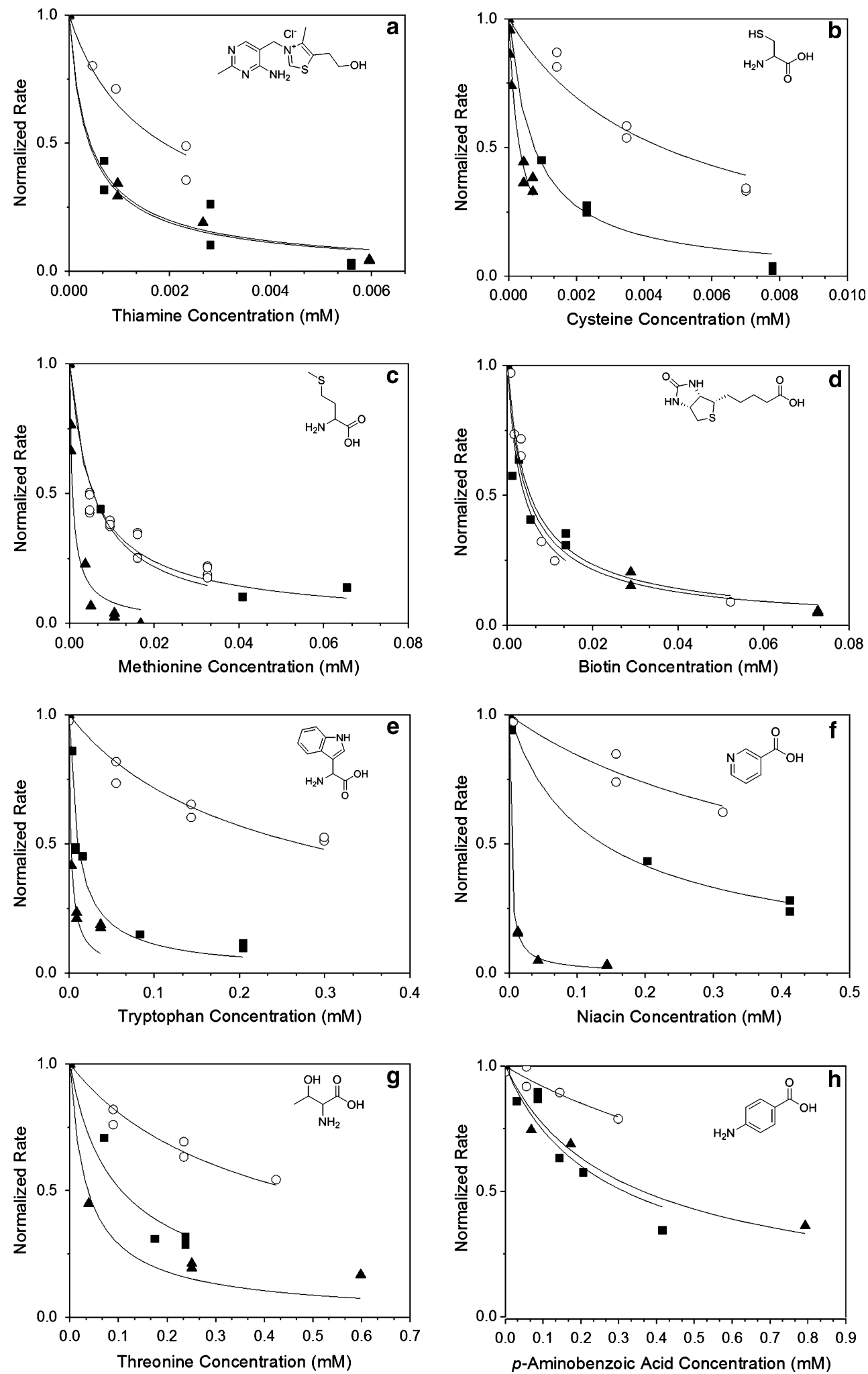

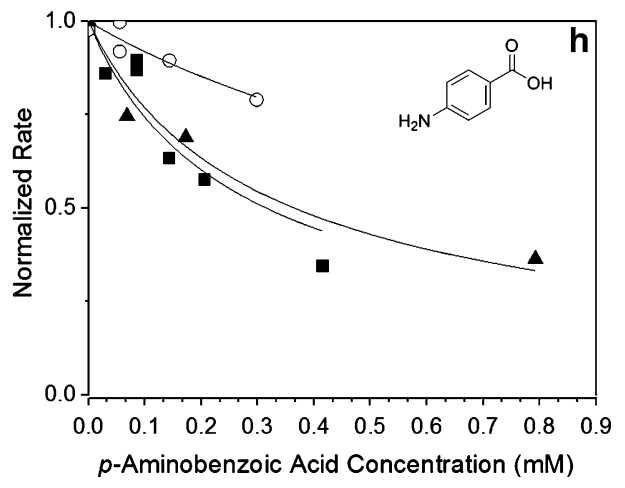

fraction of the sites on each. The strong inhibition could be due to the presence of either the sulfur atom or the $\mathrm{Cl}^{-}$ion that balances the positive charge in thiamine. The fractional uptake suggests that thiamine may decompose to leave atomic sulfur on the metal surface, although it may also be a result of the molecule adsorbing on an ensemble 
Table 3 Apparent adsorption equilibrium constants that show the inhibitory effect of a series of biogenic impurities on $\mathrm{Pt}, \mathrm{Pd}$, and $\mathrm{Ni}$ catalysts (uncertainties correspond to $95 \%$ confidence intervals)

\begin{tabular}{lccc}
\hline & $\mathrm{K}_{\mathrm{ads}} / 10^{4}(\mathrm{Pt})$ & $\mathrm{K}_{\mathrm{ads}} / 10^{4}(\mathrm{Pd})$ & $\mathrm{K}_{\mathrm{ads}} / 10^{4}(\mathrm{Ni})$ \\
\hline Thiamine $\mathrm{HCl}$ & $149 \pm 71$ & $31 \pm 9$ & $140 \pm 33$ \\
Cysteine & $133 \pm 36^{\mathrm{a}}$ & $23 \pm 5^{\mathrm{a}}$ & $310 \pm 73^{\mathrm{a}}$ \\
Methionine & $11 \pm 4$ & $15 \pm 2^{\mathrm{a}}$ & $87 \pm 32$ \\
Biotin & $15 \pm 9$ & $11 \pm 3$ & $13 \pm 4$ \\
Tryptophan & $6 \pm 3$ & $0.2 \pm 0.04$ & $26 \pm 14$ \\
Niacin & $0.4 \pm 0.1^{\mathrm{b}}$ & $0.1 \pm 0.03^{\mathrm{b}}$ & $31 \pm 4$ \\
Threonine & $0.6 \pm 0.2$ & $0.12 \pm 0.02$ & $1.6 \pm 0.6$ \\
$p$-Aminobenzoic acid & $0.2 \pm 0.08$ & $0.04 \pm 0.02$ & $0.2 \pm 0.08$ \\
\hline
\end{tabular}

a Assuming that one inhibitor molecule occupies a single site

b The equilibrium concentration was determined based on the decrease in rate and assuming a niacin:metal stoichiometry of 0.67 [32]

of atoms. Saturation coverage for biotin is $0.2 \mathrm{ML}$ on each metal, and all three metals are inhibited equally. The observation that biotin is the least inhibitory of the sulfurcontaining compounds, combined with its low observed uptake, may indicate that biotin adsorbs on a large ensemble of atoms.

Biogenic impurities that do not contain sulfur can also inhibit reduced metal catalysts, although not as strongly as those impurities containing sulfur. Tryptophan and niacin are more inhibitory than threonine and $p$-aminobenzoic acid, which suggests that $\mathrm{N}$-containing, unsaturated heterocycles bind more strongly to the metal surface than do free amino groups. Indeed, neither threonine nor $p$-aminobenzoic acid significantly inhibit the catalyst, which suggests that amine and carboxylic acid groups are not strong inhibitors of these metals. Additionally, it is notable that the saturation coverage of $p$-aminobenzoic acid is lower than that of threonine, which is likely due to steric constraints imposed by the aromatic ring of $p$-aminobenzoic acid.

Niacin likely binds in a similar fashion as pyridine, where the ring adsorbs through the $\mathrm{N}$-atom in a tilted configuration [37]. In contrast, tryptophan may adsorb with both a flat and tilted configuration on Pt and Pd surfaces, as has been described for cinchona alkaloids that contain a quinoline ring analogous to the indole ring of tryptophan $[37,38]$. However, the distribution of adsorbed configurations is different on Pt and Pd [37], which may be reflected in the different tryptophan coverages for these two metals. Additionally, it has been observed that cinchona alkaloids, used as chiral modifiers, substantially decrease the rates of hydrogenation for Pt and Pd catalysts [39]. Notably, the extent to which Pt is deactivated by cinchonidine is greater than that to which Pd is deactivated, which parallels our observations about inhibition by tryptophan.

The degree to which each metal is inhibited by niacin is inversely proportional to the ease with which pyridine derivatives are hydrogenated on each metal. While pyridine is a strong inhibitor at these conditions, pyridine derivatives that contain a carboxyl group can be readily hydrogenated at mild conditions using Pd [29], which we observe to be the least inhibited by niacin. Importantly, when using higher concentrations of niacin and larger amounts of the Pd catalyst at the same temperature, we observed nipecotic acid, which is the hydrogenated form of niacin. Pt is less active for the hydrogenation of pyridine derivatives [29], and we found that Pt was more strongly inhibited by niacin. It has been noted that Raney $\mathrm{Ni}$ requires high temperatures to form piperidine derivatives [29], and we show that $\mathrm{Ni}$ was completely inhibited by niacin.

It is significant that low concentrations of all eight species inhibit all three common hydrogenation catalysts. This inhibition dictates that care must be taken when using biologically-derived feedstocks. Hydrogenation of biologically derived species will require rigorous purification upon recovery of the reactant from the cell culture media. Importantly, there are general trends exhibited by all of the biogenic species investigated here. For example, these species all contain polar functional groups, which can be exploited in the design of both catalysts and separation schemes because the products of biological reactions are often less polar than these impurities. We have recently demonstrated this concept by using microenvironments to control the surface properties of Pd, PdAu, and Ru catalysts, and in doing so we stabilized the catalysts during the hydrogenation of triacetic acid lactone recovered from complex cell culture media [19]. A similar approach could be applied to other metals and reactions, leading to a class of catalysts that is stable in the presence of the types of biogenic compounds investigated here. Other common features, such as the prevalence of basic nitrogen groups, can be used to design separation schemes that can selectively remove these impurities from process streams, and the combination of new purification schemes with novel catalysts that are resistant to inhibition will lead to viable processes for the upgrading of biologically-derived feedstocks.

\section{Conclusions}

We have demonstrated that $\mathrm{Pt}, \mathrm{Pd}$, and $\mathrm{Ni}$ are inhibited by low concentrations of representative biogenic impurities. In particular, sulfur-containing species are strongly inhibitory for these three metals, and the strength of inhibition is proportional to the metal-sulfur adsorption energy. A similar trend was observed for other impurities, all of which contain nitrogen. In this case, the strength of inhibition is proportional to the metal-nitrogen adsorption 
energy. We note that while the effects of biogenic impurities on metal catalysts have not yet been well-studied, these species contain functional groups that are common inhibitors of metal catalysts. In general, care must be taken when upgrading biologically-derived feedstocks. Biogenic impurities can easily be co-recovered with the reactant, and viable processes for upgrading such feedstocks will require a combination of new purification schemes and novel catalysts that are resistant to inhibition.

Acknowledgments This material is based upon work supported by the National Science Foundation under Award No. EEC-0813570. T. J. S. acknowledges support from the National Science Foundation Graduate Research Fellowship Program under Grant No. DGE1256259. Any opinions, findings, and conclusions or recommendations expressed in this material are those of the authors and do not necessarily reflect the views of the National Science Foundation.

\section{References}

1. Bozell JJ (2008) Clean-Soil Air Water 36:641

2. Wettstein SG, Alonso DM, Gurbuz EI, Dumesic JA (2012) Curr Opin Chem Eng 1:218

3. Werpy T, Peterson G (2004) Top value added chemicals from biomass. Pacific Northwest National and National Renewable Energy Laboratories, Richland

4. Bozell JJ, Peterson GR (2010) Green Chem 12:539

5. Nikolau BJ, Perera M, Brachova L, Shanks B (2008) Plant J 54:536

6. Shanks BH (2007) ACS Chem Biol 2:533

7. Vennestroem PNR, Christensen CH, Pedersen S, Grunwaldt J-D, Woodley JM (2010) ChemCatChem 2:249

8. Schwartz TJ, O'Neill BJ, Shanks BH, Dumesic JA (2014) ACS Catal 4:2060

9. Zhang Z, Jackson JE, Miller DJ (2001) Appl Catal. A 219:89

10. Cortright RD, Sanchez-Castillo M, Dumesic JA (2002) Appl Catal. B 39:353

11. Luque R, Clark JH, Yoshida K, Gai PL (2009) Chem Commun 45(35):5305

12. Deshpande RM, Buwa VV, Rode CV, Chaudhari RV, Mills PL (2002) Catal Commun 3:269
13. Chia M, Schwartz TJ, Shanks BH, Dumesic JA (2012) Green Chem 14:1850

14. Minh D, Besson M, Pinel C, Fuertes P, Petitjean C (2010) Top Catal 53:1270

15. Ran N, Knop DR, Draths KM, Frost JW (2001) J Am Chem Soc 123:10927

16. Wilson YM, Dürrenberger M, Nogueira ES, Ward TR (2014) J Am Chem Soc 136:8928

17. Poizat M, Arends IWCE, Hollmann F (2010) J Mol Catal B Enzym 63:149

18. Zhang Z, Jackson JE, Miller DJ (2008) Bioresour Technol 99:5873

19. Schwartz TJ, Johnson RL, Cardenas J, Okerlund A, Da Silva NA, Schmidt-Rohr K, Dumesic JA (2014) Angew Chem Int Ed 53:12718

20. Madon RJ, O’Connell JP, Boudart M (1978) AlChE J 24:904

21. Gonzo EE, Boudart M (1978) J Catal 52:462

22. Boudart M, Cheng W-C (1987) J Catal 106:134

23. Spiewak BE, Shen J, Dumesic JA (1995) J Phys Chem 99:17640

24. Canton P, Fagherazzi G, Battagliarin M, Menegazzo F, Pinna F, Pernicone N (2002) Langmuir 18:6530

25. Bartholomew CH, Pannell RB (1980) J Catal 65:390

26. Price RH, Schiewetz DB (1957) Ind Eng Chem 49:807

27. Hussey AS, Keulks GW, Nowack GP, Baker RH (1968) J Org Chem 33:610

28. Kinoshita T, Kasahara Y, Nimura N (1981) J Chromatogr 210:77

29. Hegedűs L, Háda V, Tungler A, Máthé T, Szepesy L (2000) Appl Catal. A 201:107

30. Madon RJ, Boudart M (1982) Ind Eng Chem Fundam 21:438

31. Leclercq G, Boudart M (1981) J Catal 71:127

32. Bratlie KM, Komvopoulos K, Somorjai GA (2008) J Phys Chem C 112:11865

33. Abild-Pedersen F, Greeley J, Studt F, Rossmeisl J, Munter TR, Moses PG, Skúlason E, Bligaard T, Nørskov JK (2007) Phys Rev Lett 99:016105

34. Herron JA, Tonelli S, Mavrikakis M (2012) Surf Sci 606:1670

35. Ford DC, Xu Y, Mavrikakis M (2005) Surf Sci 587:159

36. Bengaard HS, Nørskov JK, Sehested J, Clausen BS, Nielsen LP, Molenbroek AM, Rostrup-Nielsen JR (2002) J Catal 209:365

37. Ferri D, Bürgi T (2001) J Am Chem Soc 123:12074

38. Ferri D, Bürgi T, Baiker A (2002) J Catal 210:160

39. Huck W-R, Mallat T, Baiker A (2000) J Catal 193:1 